\title{
Eleven
}

\section{THE FORMALIZATION OF VALUE}

And of course, the mere fact that many people have thought that goodness and beauty were subjective is evidence that there is some great difference of kind between them and such predicates as being yellow or containing a balance of pleasure. But what the difference is, if we suppose, as I suppose, that goodness and beauty are not subjective... I confess I cannot say. ${ }^{1}$ G. E. Moore

Axiology or the science of values will be a system of evident and invariable truths, of a type similar to mathematics. ${ }^{2}$ José Ortega y Gasset.

\section{The Non-Reality of Value}

José Ortega y Gasset's Introducción a una Estimativa (Introduction to a Science of Values) intends to determine the systematic import of a science of axiology. Within this subject it plays a threefold role: it is the closest possible approach of analytic reason to synthetic reason; it is a determined yet impossible attempt of analytic reason to encompass within its own framework synthetic reason and its formalization of the subject matter; and, with its notion of the irreality of value, it is an ingenious but futile expedient of analytic reason to find a way out of its impasse. It represents, so to speak, analytic reason beating against the barriers of its own understanding.

To see all of this, Ortega's essay must be studied hermeneutically. The first section of this chapter is a commentary on his essay (which I have translated into English). It will serve as a summary of the history of value theory. Ortega's essay has the subtitle: "What are Values?" and is divided into seven sections and an introduction. In the introduction the author tells us that traditional philosophers freely used the words "good," "value," and other value concepts without ever specifying their meaning. The word "value" itself was not found before the end of the nineteenth century, and even then it was used mainly in the sense of economic value. As Ortega explains,

It was the English who, more than others, had an idea, though a vague one, of the subject that interests us so much today. In the works of Hutcheson, Shaftesbury and even Adam Smith one breathes the atmosphere which, more clarified, surrounds today the theory of value. The first thinkers who discovered Value as an independent scientific problem, however, were Herbart (1776-1841), Beneke (1798-1854), and Lotze (1817-1881). It may be noted, by the way, that the so-called 'philosophy of value' (Windelband, Rickert, Münsterberg) has hardly any- 
thing to do with the 'theory of value' which occupies us today. In Ethics and Aesthetics, in Sociology and Psychology, the term 'value' is being used all the time without anybody's trying to examine its meaning in a special investigation. Kant, in his ethical writings, especially the Foundations of the Metaphysics of Morals, speaks several times on every page of 'value,' and not marginal to the argument or fortuitously, but in the most substantial way. The decisive themes of the Kantian moral system are planted and resolved in formulas where the word 'value' has a prominent position. Again and again we read expressions such as 'absolute value,' 'relative value,' 'intimate value of a person,' 'moral value,' etc., without Kant's ever offering us, in order to determine the weighty meanings he associates with the word, at least a nominal definition of value, let alone a considered investigation of the objective problem which the term raises.

What is true of Kant is also true of Nietzsche, who, though he speaks of the transvaluation of values, "takes recourse to the word 'value' precisely when all other concepts seem to be useless for the understanding of certain phenomena." He uses the word without systematic import, which, says Ortega,

is equivalent to recognizing that where one speaks of value there exists something irreducible to any other category, something new and distinct from all other aspects of being. Would he then not be obliged so much the more to state with a little more precision in what consists what we call value?

The purpose of Ortega's essay is to make up for this failure of traditional philosophy: "I would like by the shortest route to lead the reader toward a clear and rigorous notion of what are values." He makes clear that by "value" he understands not a species of value but value in general; he thus avoids the moral fallacy. "Our subject, then, is not a particular class of value; not what is moral value or economic value or aesthetic value but what is value in general is the goal of our investigation." $\mathrm{He}$ is astonished at the magnitude of the task, and the fact that it still is a task.

It is strange beyond imagination that such an essential and extensive problem appears before us as a terra incognito. We are in effect before the paradoxical situation that, while philosophy from the beginning has attended to the problem of being, its equivalent in extension and dignity, the problem of value, seems hardly to have been dealt with, if it has not entirely been ignored, by philosophers. 
So, while natural philosophy has elaborated its subject matter, fact, to the point of offering us the dominion of the universe, the whole second half of the world, value, has not been elaborated at all. It is still terra incognito. Charles Hartshorne has also noted a century-long sloppiness of philosophers which "staggers the imagination" in another central field, that of ontology. ${ }^{3}$

The subject has not been totally disregarded. As noted many times in this book, it can be clarified only by means of the instrument I called the axiological fallacies. Ortega y Gasset says almost the same: "Such a radical subject does not tolerate to be passed over.... The subject appears in one way or another in the body of science. Sometimes it is confused and mixed up with other problems...." This means that the metaphysical fallacy has been committed and that the problem of Being and that of Value have been confounded. At times, "the problem appears hidden under some of its particular forms," which means, the commission of the moral fallacy. At other times, "its presence will consist precisely in an aggressive absence like in a mosaic where the missing piece makes its lack stand out in the exact profile of the hole." Here we are reminded of positivism, which, in this manner, circumscribes negatively the problem of value.

Ortega y Gasset is particularly clear about what I have called the moral fallacy. As he expressed it,

The version in which Value has most frequently chosen to hide itself is the idea of the Good. For centuries it was this idea which has most closely approximated thought to life, to the idea of the valuable. But, as we shall see soon, the good is nothing but either the substratum of value or a class of value, a species of the genus value. When one does not possess the truly generic idea, the species converts itself into a false genus of which only the specific characteristic is known.

This is a classic characterization of the axiological fallacies, especially the moral, and that of method. Ortega y Gasset clarifies the fallacy with an analogy from natural philosophy.

For the primitive thinkers of lonia there existed no other objects than the corporeal or physical ones. No other class of objects had yet entered into their field of awareness. Consequently, for them there did not exist the distinction, so obvious for us, between Being itself and physical or corporeal being. Only the latter was known to them. Therefore, body and being were synonymous for them. Being was defined by corporeality, and their philosophy is physiology.

Pythagoras discovered incorporeal objects and, consequently, general and formal being, just as we today are discovering general and formal value. 
Pythagoras makes the dramatic discovery of some objects that are incorporeal and yet oppose the same resistance to our intellect as corporeal objects to our hands. These are the numbers and the geometrical relations. In view of this, it is not possible, when speaking of Being, to mean corporeality. Besides it, there is, as another species of being, the ideality of mathematical objects. Such duplication of beings makes us aware of our former ignorance about being. We knew the species of corporeality but not what of the genus of Being is in it.

Thus was discovered an ideal and formal frame of reference in whose terms we could explain corporeal being, as was done by Pythagoras in applying his mathematics to musical strings and to the measurement of distances by means of triangles and rectangles. Ortega applies this analogy to the problem of Value.

Analogically, on speaking of Good, we arrive only at a specific form of value without suspecting behind it the genus value. We have an immediate proof that the genus is something very different in the simple consideration that the Good and the Bad exclude one another, are contraries one of the other, and yet are both values: good a positive value, bad a negative value. What then is this norm 'Value' common to both and specified thus in contrary characteristics?

Behind the specific values of our lives is a Value that is as purely formal as the mathematics of Pythagoras, and which is manifested, for example, in the formal opposition of good and bad. The question then is, "What is this value in general?" That Value exists is not in question.

Each thing, says Ortega, can be regarded as both fact and value.

The consciousness of value is as general and primitive as the consciousness of objects. It is difficult for us to limit ourselves, when confronted with something, to the apprehension of its actual constitution, its qualities, its causes and effects. Beside what a thing is or is not, was or could be, we have in it a rare, subtle character in view of which it seems to us valuable or valueless. The circle of things that appear to us indifferent is very much more limited and abnormal than it seems at first glance.

Not only is everything both a fact and a value, but also the order of things, the universe itself, is on the one hand fact, on the other value. There are, then, two different orders: the factual and the valuational.

We perceive objects, we compare and analyze them, we add them, order them, and classify them. Investigating their mutual relations we chain 
them together in series of causes and effects, series which in their turn are reciprocally articulate, forming the structure of the universe, unlimited in space and in perpetual flux in the course of time. But these same objects, organized in a world according to what they are or are not, are also organized, without abandoning their spatio-temporal position and condition, in a universal but distinct structure for which it is not decisive what each thing is or is not, but what it is worth or is not worth, is worth more or worth less. We do not content ourselves, then, in perceiving, analyzing, ordering, and explicating things according to their being but we esteem them or disesteem them, prefer them or defer them, in sum, value them. And if as objects they appear to us offered in the spatiotemporal series of cause and effect, as values they appear arranged in a very wide hierarchy constituted by a perspective of valuational features.

For Ortega, as for formal axiology ${ }_{,}^{4}$ two worlds exist, the world of fact and the world of value. "If by world we understand the unitary ordering of objects we have two worlds, two distinct but complementary orderings: the world of being and the world of value. The constitution of the one lacks validity in that of the other." Thinking has to distinguish and to keep separate the two worlds; otherwise it commits the metaphysical fallacy.

Each of these worlds has its own language.

In the popular vocabulary there are words that refer especially and exclusively to the world of value: good and bad, better and worse, valuable and worthless, precious and cheap, estimable, preferable, and so on. Although this valuational language is quite rich, it forms a hardly perceptible corner of estimative meanings.

The language of value is very much richer than the realm of these words. What then, he asks, is the difference between ordinary and value language? Unfortunately, he is not much clearer about this difference than the value philosophers he castigates. Previously, he said that the character of value is "rare and subtle," and he now says that the causes of this difference are so deep that he cannot discourse about them in his essay. The same thing happens here that happens in all philosophies of value, with the possible exception of G. E. Moore: the exact essence of value, the problem, is postponed for the next occasion, and that occasion never arrives. ${ }^{5}$ No essay by Ortega $y$ Gasset delves into these deep causes, and, actually, Ortega despaired of his incapacity for precision in this vital matter.

Perhaps it is as unnecessary to examine these deep causes in the science of axiology as it was unnecessary in natural science to inquire into the causes of phenomena. Newton did not examine the causes of gravitation; he was content with the phenomenon. The why did not interest him, only the what 
and the how. The core of value is revealed in value language; for understanding value it is not necessary to go back to why this is the case; it is enough to know that and how it is so. Precisely by abstracting from the causes of the difference between valuational and factual language, and by concentrating his attention on this very difference, Ortega does come very close to the essence of value, almost as close as $\mathrm{G}$. E. Moore.

For deep reasons (causas), about which it is not possible to discourse in this essay, there exists in language the economic tendency to express value phenomena by way of a halo of complementary meaning that surrounds the primary realistic meaning of the word. Thus the word 'noble,' in phrases such as 'noble action,' 'noble character,' signifies primarily a certain actual constitution of some external or internal movements of the person, or a certain constant predisposition which the soul of an individual actually possesses. This primary significance, then, refers to actual things or qualities, just as the word 'red' refers to this chromatic quality which I am now seeing. But it would be wrong to assert that this fully satisfies the meaning of 'noble.' When I say red I refer exclusively to the color having this name; but when I say 'noble action' I do not limit myself to naming a certain class of definite acts but give to understand, en passant or complementarily, that this class of definite acts has a positive value as against the negative value which another class of definite acts have which I call 'abject.' And if we would insist in our analysis of what we understand by the word 'noble' within axiology, we would note that we do not merely declare that such acts have any positive value in general - for by qualifying an action as 'useful,' we also attribute a positive value even though one very different from the value 'nobility.' By 'noble' we understand then a definite positive value. In the same way, the words 'generous,' 'inelegant,' 'crude,' 'weak,' and 'vulgar' signify at the same time realities and values. And, what is more, if one would make an exploration of the dictionary with an intent to assemble all words of completely axiological meaning one would be astonished at the fabulous rhapsody of value characters and aspects there are in everyday language.

Ortega y Gasset here puts his finger on the central point of axiology, the axiological relation: the difference between ordinary and value language, and the double meaning of value words which do imply, in some way, a real or factual meaning. The question is: precisely what is this double nature of value words? G. E. Moore, in most exact terms, has shown this character of value words; but he has not broken through to their exact logical significance. Ortega y Gasset approaches almost as close to the logical essence of value as G. E. Moore. What, he asks "with some rigor and urgency," are these values? 
He begins to answer the question, clarifying what Moore calls the "naturalistic fallacy."

The title of the first section of Ortega's essay is: "Values Are Not Agreeable Things"; that of the second is: "Values Are Not Desired Or Desirable Things." The idea that a thing is valuable when it pleases and in the degree to which it does, he says, is the first that occurs to us when we think of value. The first and most primitive consideration about value comes to the conclusion that the valuable is the pleasing. G. E. Moore also says that pleasure is the first conclusion at which a person arrives who begins to reflect on ethics.

Hedonism is, for a sufficiently obvious reason, the first conclusion at which anyone who begins to reflect upon Ethics naturally arrives. It is very easy to notice the fact that we are pleased with things....But it is comparatively difficult to distinguish the fact that we approve a thing from the fact that we are pleased with it. It is very difficult to see that by 'approving' of a thing we mean feeling that it has a certain predicatethe predicate, namely, which defines the peculiar sphere of ethics. ${ }^{6}$

Moore calls hedonism "a vulgar error." Another writer, J. V. Langmead Casserley, says that this type of theory will "attract intelligent and good-natured men who lack acute ethical perception and profound moral experience."?

Ortega y Gasset is more generous than these two authors in discussing hedonism, especially in the form of the Austrian axiological school, represented by Alexius Meinong. For Meinong, value is the complexion that the subject's sentiments of pleasure and displeasure throw over the object. Things are not in themselves valuable; every value originates in a previous valuation, and this consists in a conception of worth which the subject puts into things according to the pleasure or displeasure they cause her or him. This view commits both the moral and the naturalistic fallacy, confusing value in general with psychological value, and psychological value with ethical value. Thus, just as Ionian ontology was physiology, Viennese ethics and all ethics following it was psychology. Ortega y Gasset shows the invalidity of this subjective view of value which, in its ultimate conclusion, leads to positivismthe "Vienna Circle"-where value is nothing but a "hole." As Ortega says,

Perhaps this view presents with the greatest clarity the error of positivism, namely, in spite of its title and aspiration - to be a philosophy of pure facts, of phenomena-always to begin by disregarding the phenomenon that it would like to explain. For it is a positive fact that, at the moment of valuing something as good, we do not see goodness projected upon the object by our feeling of pleasure but on the contrary as coming, as imposing itself upon us, from the object.... It is fit to speak of 
more or less clarity in the seen, but not of more or less intensity in the 'seeing.'

Ortega y Gasset's argument, similar to G. E. Moore's on "intuition," may not be entirely correct; "more or less clarity in the seen" may, and perhaps must, be combined with "more or less intensity in the seeing." Yet, it certainly is correct that a distinction must be made between the psychological intensity accompanying a value and the value itself. "All these considerations," he says, "move us to separate value from feelings, acts or appetites, which, it is true, always go together in our soul with valuation, motivated or awakened, stimulated or repressed by it, but which are not the same as valuation." He thus warns against the same confusion of emotion and value that we find in the emotivists and which, according to Nicolai Hartmann, is the fundamental confusion between Gefühl and Wettgefühl. The second is no more "feeling" than is, say, musicality. ${ }^{8}$

Ortega begins the positive discussion of value in his third section entitled: "Values Are Something Objective and Not Subjective." Like John Dewey, he begins with the equivocal term "desirable." In the first place, "desirable" signifies what Christian von Ehrenfels says-"the possibility of being desired." This is the psychological sense of value we have rejected.

But in the second place, 'desirable' signifies not being desired now or tomorrow or at some instant by anybody but deserving to be desired, being worthy of it, even though in fact nobody ever does desire nor, in a way, can desire it. The 'deserving,' the 'being worthy of,' is in this sense a quality of things independent of the acts of pleasure or desire that the subject exercises with respect to these things. The question is then, on the contrary, that of a claim made upon us by the object. As the yellow of the lemon requires us to judge 'that it is yellow and not blue,' thus the goodness of an action and the beauty of a picture appear to us as imperatives from these objects which descend upon us-and in virtue of which our wishes and sentiments acquire a certain character of being adequate or inadequate, correct or erroneous. Exactly for the same reasons that we consider it false to attribute to a white object the quality of black, we consider it an error to react to an object that appears to us as good with a sentiment of antipathy or repulsion.

Indeed, says Ortega with reference to Nicolas Malebranche, values are to such a point objective that not even God can change them. "Dieu ne pouvant pas vouloir que les volontés qu'il a créés aiment davantage un moindre bien qu'un plus grand, bien, c'est a dire, qu'elle aiment davantage ce qui est moins aimable que ce qu'est plus aimable." For Malebranche, values 
('good,' 'bad') are to such an extent objective that in God himself the possibility of modifying the law or norm of our valuations is excluded.

As does Dewey, so Ortega uses the suffix "-able" as a wedge for the objective nature of value. Hidden within this suffix is the purely formal nature of value. The Latin "-bilis" originally meant repetition, then generalization, finally universalization. The corresponding German suffix is "-wert," as in begehrenswert. Ortega writes,

In the meaning of the 'desirable' as that which is worth being desired, we catch a glimpse, as through a crack, ${ }^{10}$ of an entirely new aspect of the problem of value: that aspect where value presents an objective character. Now we may observe that also the 'pleasurable' contains this transcendent meaning. It is pleasant not as that which actually does or may please, but as that which deserves and demands our pleasure. The same is true of the lovable, which is what is worthy of being loved even though we may not love it actually. It is not then our desire or our love, it is no act of the subject whatsoever that gives value to a thing. It is impossible to arrive at a sufficient notion of Value while, in looking for it, supposing it is essential for values to be goals of our interests or appetites....Values have their validity before and independently of the way they function as goals of our interests and our sentiments. Many of them are recognized by us without its occurring to us to desire or to enjoy them.

Ortega's clear intuition of the objectivity of values makes him again and again denounce the axiological fallacies, although ad hoc, and not within a consistent logical framework.

It is an even denser error to define values, as does Schwartz in his Psychology of Will, 1901, p. 34, by saying: 'We call value all terms mediate or immediate of will.' In this error coincide all those who plant the problem of value exclusively within ethics. Ethics tries to find the principles and norms of voluntary action. Voluntary action consists in setting oneself ends. These ends are good or bad, that is, they are positive or negative values (by themselves, as St. Thomas holds; by the intention or prevision of their consequences, as the utilitarians maintain; by the character of conscience which decides them, as Kant thinks). From all this, to be sure, there is only one step to invert the proposition: Our ends are values hence values are our ends. Always the species trying to absorb the genus!

Always the moral fallacy! 
William Shakespeare already knew all this. In Troilus and Cressida, when Hector and Troilus are discussing the case of Helen, the poet divides among them the two theories of value, the objectivist and the subjectivist. ${ }^{\prime \prime}$

Hector. Brother, she is not worth what she doth cost.

The keeping.

Troilus. What is aught but as 'tis valued?

Hector. But value dwells not in particular will:

It holds his estimate and dignity

As well wherein 'tis precious of itself

As in the prizer.

In the sequence, Hector is more explicit on the moral law:

Hector. Paris and Troilus, you have both said well;

And on the cause and question now in hand

Have glozed, but superficially; not much

Unlike young men, whom Aristotle thought

Unfit to hear moral philosophy.

The reasons you allege do more conduce

To the hot passion of distempered blood

Than to make up a free determination

'Twixt right and wrong; for pleasure and revenge

Have ears more deaf than adders to the voice

Of any true decision. Nature craves

All dues be rendered to their owners. Now

What nearer debt in all humanity

Than wife is to the husband? If this law

Of nature be corrupted through affection,

And that great minds, of partial indulgence

To their benumbed wills, resist the same.

There is a law in each well-ordered nation

To curb those raging appetites that are

Most disobedient and refractory.

If Helen, then, be wife to Sparta's king,

As it is known she is, these moral laws

Of nature and of nations speak aloud

To have her back returned.

On the basis of these correct but frail foundations, Ortega y Gasset concludes: "Value then presents itself to us as an objective consistent character, of positive or negative rank, which the act of valuation recognizes." In other words: There is value and disvalue, and they are objective. "To value is not 
to give value to that which by itself did not have it; it is to recognize a value evident in the object." Both Ortega and G. E. Moore agree that there is value and that it is outside of us. But what this value is neither Moore nor Ortega can say.

This section of Ortega's essay does not offer us a characterization of value; it merely affirms that there is value, that it is no illusion and no subjective state. In the fourth section, Ortega tries to determine more closely the character of value. The title is: "Values Are Unreal Qualities Residing in Things." The term "unreal" in the sense of "not real" or "not empirical" leads us close to the nature of value.

"Values," says Ortega y Gasset "are...a strange, subtle cast of objectivities which our consciousness encounters outside of itself as it encounters trees and people." When we read in philosophy words such as "strange," "subtle," and "in some way," we always suspect that the author has not achieved clear sight of his subject matter. ${ }^{12}$ Yet, the following analysis approximates to the very core of value.

It is necessary to distinguish values from the things that have value. Things have or do not have value, they have positive or negative value, higher or lower value, value of this kind or of that kind. Value, then, is never a thing but is had by a thing. Beauty is not the picture but the picture is beautiful, contains or possesses the value beauty. In the same way the elegant suit is a valuable thing, that is to say, a reality in which resides a determined value: elegance. Values present themselves as qualities of thing.

The question Ortega y Gasset then puts to himself is to know what kind of qualities they are, and here he comes even closer to the analysis of G. E. Moore.

Let us look in the elegant suit, with these our eyes, for this elegance. Vain search. We see its color, its form, which are real ingredients of the suit. Its elegance is not visible-it is an unreal quality which does not form part of the physical components of the object.

What Ortega y Gasset here calls an unreal quality, G. E. Moore calls a "non-descriptive" one: the value quality of something is not a quality that is real or descriptive, that is to say, a sense quality of any kind. Yet, it is a quality, and since it is known what it is not rather than what it is, it must be determined by limitations: it is a non-real or non-descriptive quality. This is the furthest point that philosophical value cognition has reached, and the task of scientific axiology is to determine positively what this unreal or non-descriptive quality is. Already at this point it is clear that the value quality, not being 
perceived by the senses, can only he grasped intellectually. This quality, says Ortega, "resides in" the real qualities; Moore says that it depends entirely on the descriptive qualities. But what exactly is this residing or this dependence is precisely the question that only a formal axiology can resolve.

Like Plato, who is equally close to the essence of value without knowing exactly its systematic import, Ortega y Gasset has to speak in terms of myth. He gives a profound interpretation of Anderson's fairy tale, "The Emperor's Clothes." The elegant invisible suit of the emperor is the pure quality of value without the sub-strata of the real properties.

One will say that an invisible suit like the kind in the fairy tale cannot be elegant, that elegance is an attribute ascribed to a certain form and color which a dress has. In truth, the elegance is the invisible value that resides in the visible lines and coloration of the suit; it is the unique worth that belongs to these real forms. But the worth itself escapes physical vision.

In other words, value is an intellectual property; it is not a physical thing. It is a synthetic a priori, like Kant's empirical thing that can be perceived, but the object character of which is an intellectual construction. As explained previously, the systematic framework that makes value a priori is precisely the logic of the descriptive properties on which it thus depends.

This then, is the essence of value. Value is not an actual property of a thing, but it depends on these actual properties in a definite logical manner. The relation between the property of value and the factual properties, then, is a logical relation, precisely the relation that gives value its systematic import. Both G. E. Moore and Ortega y Gasset knew that this relation is logical; but they did not know what kind of logical relation it is. Their concept of value, therefore, even though it is very close to having systematic import, does not have it. The word "value" is for them no more than a word designating a very clear intuition, but still only an intuition. It is something given in a more or less mystical manner, even though Ortega, like Moore and the phenomenologists, considers the reality he intuits so certain as not to be mysterious.

Will it then not be said that these values are mysterious natures which, like Platonic ideas, escape our sublunar vision and inhabit a super-celestial place? Not at all. Values are not things, they are not realities; but the world of objects - even excluding all pseudo-real mysticism - does not consist only of things. A number is not a thing, but it is indubitably an object, as clearly and even more clearly than any thing.

Here Ortega y Gasset, in comparing values and numbers, states the formal nature of value: values are logical entities, as are numbers. But since he 
does not know what kind of logical entities they are, it is all but mystical to say what he says. The same mystical insight is found in the axiologies of Plato and G. E. Moore. ${ }^{13}$ Yet, the perspicacity of Ortega y Gasset is truly clairvoyant. Value, he tells us, is a property such as similarity, equality, and similar proportions which cannot be perceived with the senses either, but can be seen intellectually.

A simple classification of the qualities which things have puts us on the secure route to comprehend the lineage of those objects which are values. Things have certain proper qualities, qualities, that is, they possess for themselves independently of their relations to other things. Thus, the color and form of the orange are qualities it has even though it were alone in the world. But when this orange is equal to another it has a new quality, equality, which is as much its own as its color and form; only that it does not have equality when it is alone, but when it is compared to another and put in relation with it. It is then not a proper quality but a relative quality. Of this type are identities, similarities, larger or smaller, etc. Well then, it is characteristic of these relative qualities not to be visible to our eyes. When we see two equal oranges we see two oranges but not their equality. The equality presupposes a comparison, and the comparison is not a work of the eyes but of the intellect. Yet, after the comparison, equality is obvious to us with an evidence equal to the visual. We can say that "we see" the equality with a non-ocular but an intellectual sight. This intellection, this understanding, is a perception of the same genus as the visual but of another species. Without it we could not say that "two and two is equal to four."

This then is the conclusion at which Ortega y Gasset's insight and penetration into the essence of value arrives. Value is a non-sensible quality sui generis, self-evident, like a logical relation.

What it is in detail he does not tell, but what he does tell helps us to draw further conclusions: "The eye sees color but it does not see sound. Number is not seen nor heard but it is understood as is equality, similarity, etc. There is a perception of the unreal which is neither more nor less mystical than the sensual." This is true only under one condition: that we have the intellectual tool to understand it. Sensual perceptions can be measured, elaborated, and explained by observation. The direct perception of number is developed and systematized in mathematics. As long as mathematical explanations were not available, numbers were "mystical," as during the time of Pythagoras, and as was the "imaginary" number that Gauss explained, by the unit circle, as an angle of $90^{\circ}$. The immediate perception of value is mystical in this same sense and will remain so unless and until there is a framework, a formal axiology, that develops and systematizes it. The "mystical" is merely 
the unknown divined; once known it loses its mystique and becomes an everyday tool.

In this respect a difference exists between the conception of value of Plato, Nicolai Hartmann, and other value realists, and that of Ortega y Gasset. Ortega does not attribute to his values the value the realists attributed to theirs; he takes them more soberly. He does not hypostatize them but puts them in their exact place: the logic of formal relations. Actually, his account of the proper and relative qualities of things gives the exact logical explanation that formal axiology elaborates. The color and form of the orange, which the orange has even if it were alone in this world, are qualities it has in itself and are parts of its intrinsic value - as developed by G. E. Moore, and logically interpreted by formal axiology. In the comparison of one orange with another we have extrinsic value, which is also based on a simple and known logical relation, namely that of class membership. Value is thus precisely what Ortega y Gasset says it is, only, he does not say it with precision. His position with respect to formal axiology is thus very similar to that of Moore: his thought leads focally into the new science. From the point of view of this science, he conforms to Alfred North Whitehead's words: "Everything important has been said before by someone who did not know he was saying it."

Ortega y Gasset's conclusion that "values are a peculiar kind of unreal objects which reside in real objects or things as qualities sui generis" shows, in the words "sui generis," his uncertainty about the nature of values. Since he does not see clearly enough that they are logical relations, and hence cannot make the necessary axiomatic identification that defines them as such relations, he has to cast about for some other explanatory form. Not finding it, in the end he must run aground, as does Theodor Lessing for the very same reason.

Actually, value qualities are not "sui generis" but qualities well known in logic, namely second-order functions, predicates of sets of predicates. Value properties characterize the set of the actual or descriptive properties of things as a set. The property of the totality of the set is the property "good." Other value properties are additional logical properties of the set. This is all the mystery there is to these properties.

This kind of logical property, of course, "cannot be seen with the eyes such as colors"; so, thus far, Ortega is right. But he next begins to go off course: "Neither," he says, "can they be understood as can numbers or concepts." Here he commits both the naturalistic fallacy and the fallacy of method. He believes that values by their essence must be felt; and he confuses this feeling of value both with psychological feeling and with the explanation of this feeling. Although Ortega sometimes says that the intuition of value is psychological, he is usually clear about the necessity to distinguish the psychological accompaniments of value from value itself. The intuition of value, then, may be said to be phenomenological rather than psychological, an intu- 
ition sui generis. But this does not mean it cannot be as clearly explained as number or concept. "The beauty of a statue, the justice of an act, the grace of a feminine profile are not things which it is fitting to understand or not to understand. It is only fitting to 'feel' them, or rather, to estimate or dis-estimate them." Unlike G. E. Moore, who never despaired of a possible knowledge of values, Ortega y Gasset made his own lack of such knowledge an epistemological necessity. Actually, values can be understood. The assertion that they cannot is the result of ignorance rather than of the proper nature of value.

The logical understanding of value leads to the axiometric structure of logical intensions ${ }^{14}$ and thus to the legitimate role of mathematics within axiology. Ortega y Gasset divines such a role for mathematics; the fifth and sixth sections of his essay are entitled: "The Knowledge of Values is Absolute and Quasi Mathematical" and "Dimensions of Value." Unfortunately, instead of raising value knowledge to mathematical clarity, he lowers mathematics to the vagueness of his knowledge of value. Thus, he commits the same transposition we examined in preceding chapters, the application of a synthetic formal frame of reference to analytic material not prepared for such application.

In spite of this, these sections of Ortega's discussion contain a richness of profound ideas about value. He is here in the great tradition of axiology that began with Plato. From the fact that "each thing around the set (repertorio) of qualities which it has and which make it such a being, has a halo of value qualities which define its value profile," Ortega infers "something of the greatest importance."

The perception of the thing as such and the perception of its values are produced with great independence one from the other. What I mean is that sometimes we see very well a thing and yet do not 'see' its values. Example: for three hundred years one has looked at the pictures of $E l$ Greco without discovering their peculiar aesthetic quality. At other times, inversely, we have the clear consciousness of certain values without the necessity of 'seeing' them realized in anything. In artistic creation this relation of value is the normal thing. The artist usually starts with the intuition of certain values which a picture or a poem must have and only then encounters the actual characters-forms, images, rhythms -in which they are incorporated. When Raphael was asked what it was that he was copying in his pictures, he responded: 'una certa idea che mi vien in mente.' This previous idea was first a pure organism of value: grazzia of lines, equilibrium, architecture, a sweet gloss of forms, etc.

The relation between the real and the unreal qualities is developed in further detail: 
Let us be very clear about the conclusion to which this statement leads. Every value, by having the character of a quality, requires to be referred to some concrete thing. Whiteness will always be the whiteness of something, goodness the goodness of someone. But occasionally we see the quality without recognizing very well its substratum, the thing or person that possesses it. On the excited surface of the sea we may distinguish a whiteness but do not know whether it belongs to a sail, a rock, or the far off foam. In the case of values the independence is greater. 'We feel' with perfect clarity perfect justice without up to now knowing what actual situation could realize it without residue.

If we knew the logical form of value in general we would also know the systematic nature of this particular aspect of it, its "independence." The logic of it seems to be that of the metaphor. The metaphor is a set of properties that has no determined reference or extension but has an intension totally independent of the qualities of any object to which it refers. ${ }^{15}$ Ortega y Gasset has to feel his way toward these logical relations through more or less picturesque everyday language.

Things, realities, are by nature opaque to our perception. There is no way in which we might see the whole of an apple; we have to go around it, open it, divide it, and we will never arrive at perceiving it integrally in its totality. Our experience of it will always be approximate but never perfect. On the other hand, the unreal, a number, a triangle, a concept, a value-are transparent natures. We see them, if we see them at all, at once in their completeness. Successive meditations will give us more detailed ideas of them, but from the first vision they give themselves to us in their total structure. All our later mental labor is based on this first vision....Our experience of number, of geometrical body, of value is then absolute. Hence metaphysics is a science a priori of absolute truths. The science of values, then, will itself be a system of evident and invariable truths, similar to mathematics.

Recall that earlier Ortega said that values confront our perception with the same resistance as concrete things. Here we have the vision of formal axiology. Ortega y Gasset not only projects this science but also distinguishes between the science itself and its application. He thus implies the possibility of the fallacy of method.

Notice that I speak strictly of the knowledge of values. The question of whether an actual thing does or does not have the value we attribute to, or presuppose in it, permits only empirical and approximate solutions. In 
the same way, our knowledge of the triangle is absolute but not the fact that an actual body is or is not rigorously triangular.

Ortega is recognizing clearly that axiology is a definite and a formal science:

It may sound strange to many but I hope continued reflection will make them recognize the inevitable conclusion. The sentence de gustibus nondisputandum is a crass error. It supposes that in the realm of 'tastes,' that is, of valuation, there exist no evident objectivities to which our disputes can be referred as ultimate recourse. The truth is the opposite: every 'taste' of ours tastes a value (pure things give no possibility for taste or distaste), and every value is an object independent of our moods.

Here we see with what consistency Ortega draws the consequences of his fundamental intuition that there is a world of values by the side of the world of facts and that this world of values is independent of the world of facts and absolute.

Of the detailed qualities of value Ortega y Gasset only knows what is obvious and what can be known without the systematic import of a system of axiology. In the sixth section, he assigns three dimensions to value: its quality, either positive or negative; its rank, either of superiority or inferiority; and its matter, the "ultimate estimative contexture irreducible to any other determination."

What consistently and in detail these three dimensions signify he cannot say. The task and the achievement of formal axiology are not only to define these dimensions but to interrelate them in a systematic manner. Ortega y Gasset has to content himself with some suggestions made at random. He says with respect to quality and rank of value: "Elegance is a positive valueas against the negative inelegance — but at the same time it is inferior to moral goodness and to beauty." Why this is so he does not tell us, but "The certainty of this subordination is not less firm than the certainty we feel when we affirm that four is less than five, and it is moreover of the same type." $\mathrm{He}$ is absolutely right, but only in the light of formal axiology, which can present these relations with logical certainty.

"In the last instance," he continues, "mathematical truth refers us to intuition and intellection of numbers. It is enough to understand well what is five and what is four to make it evident that four is smaller than five." This obviously simplifies mathematics somewhat. The relation between four and five is not a business of intuition but of definition within an axiomatic system. He continues: "It is sufficient also to 'see' well what is 'elegance' and what is 'moral goodness' in order that the former appear as objectively inferior to the latter." As is seen, the analogy between Ortegian axiology and mathematics 
requires imperatively the systematization of axiology. Instead, Ortega y Gasset simplifies mathematics in an illegitimate manner. He commits the same error as the positivists against whom he polemizes. They, instead of amplifying logic so that it can explain value, negate value because it does not fit into the simple logic they employ. Ortega y Gasset, because he does not know the axiological system, simplifies mathematics, and thus instead of amplifying axiology in the axiomatic manner of mathematical logic, he cuts mathematics to the measure of his valuational ignorance.

Neither can he tell us what is the matter of value:

The fact that elegance is unique in itself, different from justice, or beauty, or utility, or skill, etc., cannot be defined, just as the color red cannot be defined, nor such and such a sound. Our awareness of it can only consist in a direct, immediate perception.

Even though Ortega gives us certain characteristics of value, and more accurately than other axiologists, in the last resort the same must be said of his axiology as he says of Friedrich Nietzsche: re refers to indefinite words just when all other concepts seem to be unservable for understanding certain phenomena. The word "intuition" plays in Ortega's axiology about the same role as the word "value," according to Ortega, plays in Nietzsche.

Another such word is the "matter" of value. It is not very helpful to the knowledge of value to be told that every value has its differential matter and that it is not merely formal, which, according to Ortega, was "the great discovery of Max Scheler." The word "matter" plays no other role in Ortegian axiology than the word "substance" in traditional metaphysics and signifies no more than what the verb "to be" signifies. Scheler, like Ortega, saw the region of value, but he has just as little succeeded in differentiating it. Both Scheler and Ortega commit the fallacy of method, fusing axiological value with some matter or substance that this value exhibits.

Actually, the "matter" of value is a matter of the application of its formal essence to certain given data. "Elegance," for example, is aesthetic value applied to garments and the like. Apples cannot be "elegant." Aesthetic value is defined in formal axiology as intrinsic value applied to things, and intrinsic value is the fulfillment of a non-denumerably infinite intension. The "matter" of value is rooted in the systematic-empirical import of the formal system of value. This specifies certain of its forms, and these, applied to specific data, bring about certain definite kinds of value, such as elegance, skill, and beauty.

Ortega y Gasset, not knowing the formal definition of value, says that "The definition of values can only be made, as that of colors, by indirect means." Here he compares value with color, as did G. E. Moore, in spite of the fact that he earlier contrasted value with color, color being a real quality and value an unreal quality. Orange, he says, 
can be defined indirectly by saying that it is a color situated in the spectrum between red and yellow. Similarly, it is fitting to reduce values to a concept determining the set of objects in which they reside and the type of subjective reactions that are adequate to them.

Here again he commits the same fallacy he commits in the analogy with mathematics, that of confusing the analytic and the synthetic. Color can be defined in the spectrum with exactness because the spectrum is part of a systematic net, namely that of optics. No similarity with the definition of value exists unless we have a systematic net for the region of value as well. The exact analogy with color would be that color can be defined by "determining the set of objects in which they reside and the type of subjective reactions that are adequate to them." It is, to paraphrase Ortega, "extraordinarily strange" that in the philosophy of value errors as obvious as this can be committed.

Ortega then asks: "What class of objects can serve as substrata or support of the value "moral'?" He should ask the same of color: "What class of objects can serve as substrata or support for the color 'red'?" He then would have to say that indirectly defining the color red would be enumerating the objects that can be red, and that some objects, for example numbers, cannot have color. He proceeds in this manner to "define indirectly" the value "moral goodness." "Evidently we cannot say in a formal sense that a stone or a plant are good. Only a being capable of action can be morally good, that is to say, a subject causing its acts. This is what we call 'person."

Ortega gives us an extensional rather than an intensional definition of "moral goodness." This presupposes a knowledge of what that goodness is, and why it is only applicable to persons. Formal axiology presupposes nothing and defines moral goodness as intrinsic value applied to persons (just as it defines social value as extrinsic value applied to persons). "Person," in formal axiology, is defined as "that being which has its own definition of itself within itself." ${ }^{\prime 6}$ Moral value, then is a specific and exactly defined application of the value system, just as physics is a specific and exactly defined application of the number system. Ortega cannot proceed in this manner because he lacks a formal system of valuation. He continues, writing that "There are then excluded as substrata of this kind of value all physical objects and all animate objects who lack will. But an imaginary person, the person of the novel, is not properly called good but only fictitiously so." Again, he touches on a vital subject, one developed in more detail by Luis Recaséns Siches. A legal person, too, is an imaginary, a fictitious person, so a state, a nation, or a corporation cannot morally be either good or bad. Moral value is a matter of individual persons. Hence, the correctness of the Nuremberg judgments, which made individuals responsible for the crimes of Nazi Germany, and the profound scruples of Americans asked to perform similar acts in Vietnam. In formal 
axiology, the same follows, but by the systematic definitions of intrinsic value as against systemic value, rather than by "self-evidence."

Ortega is equally clear and definite with respect to aesthetic value, but equally "intuitive." He says,

'Beautiful' can be landscapes, rocks, plants, and animals, and they can be so in the full sense of the word even though they may be imaginary. A painted landscape can be beautiful not only as a real painting but also as that imaginary landscape. The value 'beauty,' which strictly is the generic term of innumerable values, is then not conditioned by the existence of its object, as is the case with moral values or those of utility.

But with what justification does Ortega assert this? Why can the imaginary be beautiful but not good? In what exactly consists the beauty of an imaginary landscape? Questions like these can only be resolved when either intuition has reached uttermost precision or when an axiological frame of reference defines aesthetic value. In formal axiology, this definition is "the application of intrinsic value to things." From this it follows that in painting a landscape, neither the painting nor the landscape can be isolated. Both form the aesthetic value precisely as this painting of this landscape, as this sensory transfinite organic whole. ${ }^{17}$

The second means for indirectly defining value appeals to the type of subjective reactions that are adequate to it. The corresponding definition of color, for example, would be a psychology of color. While this has its significance, as in psychological tests or subliminal responses, it would hardly be an aesthetic definition; rather it would commit the naturalistic fallacy. The realm of color could be used as an analogue for that of value, as is done suggestively by Raymond Ruyer. ${ }^{18}$ Ortega himself does not follow up his own comparison between color and value. He considers the feeling reactions only with respect to values.

To beauty corresponds pleasure and enthusiasm but not respect....Admiration is a feeling which corresponds more to the creation of a work than to the work.... The good act cannot be directly subject to pleasure but to respect. Respect is the emotion congruent to virtue. Utility... is a kind of value before which a feeling of respect and pleasure is unfitting. The end which the useful achieves arouses, perhaps, pleasure, but the useful itself only provokes a peculiar emotion of satisfaction, a feeling without temperature, very fitting to the rational, frigid character of the value 'utility' itself, etc.

All these are indeed observations pertinent to a science of axiological psychology. But, as they stand in the essay, they are no more than suggestions 
without any interrelation with the rest of the work. Again, what is missing is systematic import.

The same is true in the seventh and last section of the essay entitled "Classes of Values." Of Ortega's list of values the same may be said that Kant says of the Aristotelian list of categories; it is a rhapsody rather than an architectonic whole. Ortega is himself not satisfied with this list. Its purpose is only to give some clearer view of what values are. "The problem of the classification of values would require very concrete observations." His table of positive and negative values presents the following six kinds of value, and representative instances:

Utility values: capable, incapable, expensive, cheap, abundant, scarce; Vital values: sane, insane, healthy, sick, select, vulgar, energetic, inert, strong, weak;

Spiritual values: intellectual, knowledge, error, exact, approximate; Moral values: Good, bad, kind, evil, just, unjust;

Aesthetic values: beautiful, gracious, crude, elegant, inelegant;

Religious values: holy, profane, divine, demoniac.

As the comparison of this table with the corresponding table in formal axiology shows, ${ }^{19}$ without an axiomatic system the classification of values has no systematic import. The kinds of value are as rich as, or richer than, value language. With reference to value language, Ortega said, "The fabulous abundance of its characters and aspects would be truly astonishing." He could say the same of the classification of values. As the classification of the expressions of value language is only possible within a systematic framework, so the classification of the values themselves is possible only within an axiological system capable of ordering the tremendous variety of the world of value. This Ortega does not give us, but he does lead us close to the intellectual comprehension of value. Even though he did not reach the goal of his essay and did not obtain a clear notion of what value is, he led us to the very door of this notion, that is, to formal axiology.

Ortega y Gasset was explicit on the great value of his vision of a scientific axiology, not only for ethics and aesthetics, but also for history and other social and human disciplines.

We have to get used to the idea that the fauna and flora of valuation are no less rich than those of nature. The qualities of value are as innumerable as the physical ones. Man is going to experience both kinds increasingly throughout his long history. One of the most suggestive investigations which the new theory inspires is the reconstruction of history as a process of the discovery of values. Each race, each epoch seems to have had a peculiar sensitivity for certain kinds of values and 
suffered...a strange blindness for others. This challenges us to determine the value profile of peoples and of great historical periods. Each would be distinguished by a typical system of valuation, the ultimate secret of its character, of which external events would be mere emanation and consequence.

Thus, it would be extremely interesting to study from this point of view the great figures whose work and genius has been the invention of values-Buddha, Christ, Saint Francis of Assisi, Machiavelli, Napoleon. And those other sovereign spirits who were not specifically 'practical' men-religious, moral, or political leaders-but who discovered new universes of value never before imagined: Michelangelo, Cervantes, Goya, Dostoyevski, Stehdhal.

All this and a thousand attractive questions more which the incredible fertility of the great subject 'value' suggests would constitute the historical counterpart to axiology or the science of value, whose laws are as perfectly evident as those of geometry. The regions of taste and of feeling, which during the last centuries have been abandoned to caprice, are about to be subjected by man to vigorous systematization. Ethics, aesthetics, jurisprudence, are entering into a new phase of their history.

Ortega y Gasset was one of the predecessors of this new phase, the new value science, and had a vision of the new world. He can be compared to Francis Bacon or Giordano Bruno in the field of natural science. He had the vision even though he lacked the method; he did not see the road but he saw its destination, which he formulated in the words of Auguste Comte at the end of his essay: "To put in order again the life of man: a systematization of feeling."

\section{The Situational Reality of Value}

The problems Ortega y Gasset defined so clearly and left to posterity to solve are the following. What exactly is the nature of the genus value, its quality sui generis? And how does it serve to order value reality? How, in other words, can the unreality of value be structured and differentiated in such a manner that value becomes intellectually understandable, and this understanding becomes practically fruitful? How, to be exact, can the knowledge of value determine the value nature of actual situations and, inversely, the value nature of these situations the knowledge of value? In a word, how can value knowledge and value reality be joined in one unity?

One path toward this goal might be trying to combine the unreality of value with the reality of value situations. This was undertaken by Risieri Frondizi ${ }^{20}$ who carries the Ortegian question one step further to its solution. Frondizi's attempt is doomed to failure because the unreality of value cannot 
be coupled with the reality of value situations; but his approach, rightly understood, leads a step beyond Ortega, toward the formal reality of value.

Frondizi's work represents the bridge between Ortega's "unreality" of value and the formal reality of value. The latter, in the isomorphism of value system and value reality, represents the goal of Ortega's quest.

Frondizi maintains the Ortegian thesis: values are non-real qualitiesneither material nor ideal-that do not add reality to objects, as do both primary and secondary qualities. They are qualities sui generis that add only value. Numbers, triangles, concepts are ideal entities; values are not. But all four are non-real. ${ }^{21}$

Frondizi finds the value quality in the polar structure of value situations, the subject and the object of valuation. He examines various experiences of value showing the complexity of their three components - value, the valuer, and valuation. But it is not immediately apparent in what way these three components, factually analyzed, are converted into valuational components. What makes valuational an object of value, and even its valuation? For example, although pleasure is experienced while drinking a glass of beer, what the objective value of the beer consists of is not clear; neither is the justification for calling pleasure a value.

If neither subjectivism nor objectivism offers a criterion of value, a subjective element of the situation such as pleasure should not be called "value" unless the valuational criterion has been established beforehand as a definitive criterion of the situation. This criterion, $X$, should not only make pleasure valuational, but also beer. But what makes the beer valuational and gives it objective value? Frondizi says,

There is beer and beer, to be judged by their physiochemical constitution. If the density, the temperature, etc., is altered, the sensation of pleasure will be different. Other objective elements are equally influential-the glass from which it is drunk, the temperature of the physical environment in which one finds oneself, etc. ${ }^{22}$

All these qualities are factual; they describe facts. In what way do they become values? According to Frondizi, any change in the configuration of these facts makes the sensation of pleasure different. The axiological problem of this sensation is, then, how to make the transition to the realm of value with two things that are not prima facie values, such as the pleasure of drinking and the circumstantial characteristics connected with it, including social and cultural factors ("Drinking a glass of beer with a friend is not the same as with an enemy"). The fundamental problem is: how do two non-axiological things form one axiological thing? According to Frondizi, "Although value may not be derived exclusively from factual elements, neither can it be divorced entirely from reality." ${ }^{23}$ So, how can the reality of the experience 
transform itself into the nonreality of value? What is the relation between the reality of the situation of valuing and the nonreality of value?

In G. E. Moore's terms, the question is formulated thus: how can the complex configuration of a natural experience give rise to a non-natural experience? In Frondizi's terms, the question concerns the way in which the reality of the experience can lead to the creation of: a) the reality of the experience of the nonreality of value, or, b) the nonreality of the experience of the nonreality of value. The axiological problem, in Frondizi's terms, consists in explaining exactly the relation between the reality of the experience and the nonreality of its value. All of the elements of the "valuation" situation are real elements - natural-both on the side of the subject and on the side of the object.

There are qualities in the object which make me react in a definite way. The aggregate of objective qualities of a painting, capable of causing a definite aesthetic feeling in this case does not appear in isolated form: the painting has a frame, it is hung on a wall which is part of a building. The size, color, and form of the frame, just as the color and size of the wall, the position of the painting in the room, etc., constitute part of the objective qualities. ${ }^{24}$

All these are real and natural qualities of fact. What in them causes my aesthetic emotion and defines the aesthetic character of my feeling? "We can enhance or reduce the value of a painting by changing the objective conditions which surround it," ${ }^{25}$ such as the lighting, the temperature of the room, its size, and so on. Are these the "objective qualities which give the great works of art their lasting value?"26 Obviously, aesthetic qualities that are not identical with these real qualities must exist - the nonreal qualities which, according to Frondizi, are values. But what are these qualities, and what is their relation to the objective qualities listed? To this point, Frondizi only gives the depository of value, that is, its objective matrix; but he does not give either the properties of value itself or the relation of these properties to the depository.

Following up on Frondizi's analysis, we can go a step further. He tells us that the set of natural, that is objective and subjective qualities, produces value, and even more, constitutes value. This is an exceedingly important assertion. It should be further developed, but such a development would lead to an area that the author explicitly closed off from his own investigation, namely, logic and methodology. ${ }^{27}$ For the axiological problem then reduces itself to: What is the relation between a whole and its parts? This is a logical problem. More specifically: What does it mean, axiologically, that the transition from the parts to the whole produces value, both in the parts and in the whole, or in the parts of the whole? This question, which necessarily follows 
from Frondizi's argument, carries us beyond the field of material axiology to formal axiology, which does not deal with specific situations, but with the concept of situation as such, defined as a set of elements, that is, as a logical entity. From such a formal axiology it follows that the nonreality of value is precisely its formality, in the twofold sense of being the form or framework of factual elements, and of being able to be apprehended only by formal considerations. There is no difference in the nonreality of numbers, triangles, concepts, and values.

Frondizi's material or situational solution demands a formal supplement. Such a supplement should take the nonreal character of value seriously, and not bury it in the materiality of situations. It should dispense with all the serial characteristics of situations until it arrives at the core of the notion of situation itself: its essential characteristic of being a set of elements. With this notion, axiology rises to a formal level.

Frondizi's solution arrives at the threshold of this conception. "If the name 'situation' is given to a complex of elements of individual, social, cultural, and historical circumstances, we maintain that values have existence and meaning only within a complete and determined situation." ${ }^{28}$ Here is the threshold. The questions that now arise-in particular, What is the relation between this intrasituational existence of value and its nonreality"? — can only be answered by an analysis of the pure concept of "situation," and not by an analysis of specific situations, that is, only by formal analysis of "situation" and not by a material analysis of situations.

Frondizi does not effect such an analysis because of an ambivalence in his conception of the "reality" and "nonreality" of value. His first chapter maintains that the fundamental characteristic of value is its nonreality. However, his last chapter does not take this nonreality seriously enough to lift us out of reality. "When we descend from the level of abstractions to that of reality, formal definitions are of little use"29 for the determination of value. But why descend from the realm of abstraction to that of reality if values are nonreal? The axiological intuition of Max Scheler and Nicolai Hartmann, says Frondizi, is worthless without "the contrast of diverse data among themselves and the analysis of the distinct situations in which they are produced." Only this "will allow us an interpretation in the light of a complete, integral experience." ${ }^{30}$ But what is the value of experience without an axiological criterion? With what justification can we characterize such an experience as a value experience? Do we not beg the question if we base this characterization on the verbal translation of "experience" as valuational experience, and the transposition of a subjective activity and an object of such activity to mean "valuation" and "value"? Is this not an analogy between "experience" and "valuational experience" rather than an analysis of the valuational experience as such? If it is true, as Frondizi maintains, that everything that can be said about experience can also be said about valuational experience, and if both 
are totalities, it is imperative for us to define the difference between the first totality and the second, that is, the difference between the situational totality and the valuational totality.

Frondizi leads us to the very core of the axiological problem. He extends, historically and critically, Ortega y Gasset's famous question: "What are values?" and takes us one decisive step closer to its answer.

\section{The Formal Reality of Value}

While Frondizi drowns, as it were, the unreality of value in the waters of empirical reality, Theodor Lessing waters it down to tautologies. He starts, as do Ortega and Frondizi, with the phenomenological uniqueness of value. But structuralization of this axiological essence peters out for lack of that of which in Frondizi there is an excess: valuational materiality. Finally, when Lessing tries to find salvation in what he lacks, it is too late, and the whole enterprise falters. An axiomatic system can have connection with reality only in its axiom, not at any later point of its development. The axiom is like the umbilical cord that nourishes the synthetic system; and without such nourishment from the world for which, in the last resort, it is made, a system dies a premature death. Yet, besides formal axiology, Lessing's is the only sufficiently protracted attempt at a Wertaxiomatik, an axiomatic of value, that exists.

As did other initiators of new philosophy, Lessing, too, calls his book "prolegomena." 31 The whole literature of axiology today consists of prolegomena toward an axiology, and the axiology of which they are prolegomena is formal axiology. G. E. Moore calls Principia Ethica prolegomena, and so does Charles L. Stevenson his Ethics and Language.

Lessing makes clear that axiology is one thing and ethics another. Thus he guards against the moral fallacy. "The connection of axiology with the practical sciences, in particular ethics, was only a historical prejudice." ${ }^{32} \mathrm{Al}$ though the book was written, as the author says "under the force of ethical and psychological thinking, its purpose was to found an eternal axiomatic more geometrico tractata which ought to be independent, as is mathematics, of material sciences such as ethics, aesthetics, philosophy of law, economics, and the modern psychology of values." ${ }^{33}$ In other words, it ought to be a formal axiology. The object of axiological philosophy ought to be the essence of value, not its esse, fieri, or effici, its being, becoming, or being caused. ${ }^{34}$

As did Ortega y Gasset, Lessing attacks empirical valuational thinking. When primitive reason recognizes that values are not "facts of life...and that the norms of experience are as little real as are rectangles and triangles then it believes they are nothing." 35 (Compare Moore's "super-naturalistic" fallacy.) The problem of value cannot be resolved by psychological, positivistic, or metaphysical concepts. Even Kant, according to Lessing, committed what we 
call the naturalistic fallacy, interpreting value as metaphysical, a "solution dictated by perplexity." 36

Lessing begins by showing the confusion in the ethics of Kant between moral rules and moral actions, which corresponds to the fallacy of method. Says Lessing, if it is clear that Kant suffers from this confusion or, as I say, this fallacy, then the moral philosopher has the obligation to ask himself what pure axiological rules can be. This leads to "the possibilities of an axiology," that is to say, a "formal or pure" science of value. He uses as the motto of the section a statement by Jules Henri Poincaré affirming that an empirical science is impossible without reference to a world of a priori, non-empirical, and constant objects.

A pure axiology! This 'pure axiology' would be 'transcendental' a priori. It would form the correlate-in the realm of practice- to pure formal logic. Thus there would belong to pure axiology all statements about value which abstract entirely from volition, valuational conduct, and valuation. That is to say, propositions such as the following: If $A$ is a positive value and $B$ is a positive value, $A+B$ is a larger positive value than $A$ and $B$ alone. If $a$ is negative value and $b$ is a negative value $a+b$ are a larger negative value than $a$ and $b$ alone, etc. This 'pure axiology' can be called arithmetic of value. At its beginning there must be unconditional, self-evident, intuitive, general axioms. From these then follow, in analogy to mathematics, demonstrative value-mathematical propositions. These value-mathematical propositions would be statements in part about the necessary form of 'value in general' and in part about the necessary essence of value in general. ${ }^{37}$

Here Lessing gives in detail what I call the systematic import of axiology. It is precisely propositions such as these that constitute formal axiology. Lessing is more detailed in his understanding of the question, "What are values?" than Ortega y Gasset, and his intuition of this new science is more elaborate and exact than that of Ortega.

Lessing sees with equal clarity the relation between value arithmetic or formal axiology and actual specific values. "The total sphere of value arithmetic is a priori with respect to any kind of actual value discipline. With respect to the 'object' value, one may call it the sphere of merely formal statements." ${ }^{38}$ From this pure and formal axiology must be separated the rules of application, which may be called normative axiology, in opposition to theoretical axiology, and which may be formulated, for example, as "If I have $A$ as a positive value and $B$ as another, I shall reasonably prefer $A+B$ both to $A$ alone and to $B$ alone." Lessing here clarifies that preference, even if synthetically seen, is a matter of application and cannot be a part of, let alone the ba- 
sis of, theoretical axiology. "If I have $a$ as a disvalue and $b$ as a disvalue then I shall reasonably avoid $a+b$ more than $a$ alone and $b$ alone." ${ }^{39}$

Lessing makes it clear that these are rules of applied axiological science in general-formal normative rules-and not rules of any specific applied axiological science-material normative rules, like the rules of the sciences of axiological psychology or ethics. ${ }^{40}$ Thus he puts us on guard against both the moral fallacy and the fallacy of method, the distinction both of the relation between axiology and specific axiologies, and between the last and their subject matter.

He who confuses the study of the object value with the study of valuable objects...is in the position of a man who, because he learned arithmetic by counting apples and nuts, assigns the study of arithmetic to botany or who, because there would be no number theory without people who count, confuses the psychology of counting with higher mathematics.

Although Lessing's thinking is very clear on the difference between pure and applied axiology, or pure axiology and its applications, he does not have a system of such an axiology. In this respect his doctrine lacks systematic import as do the other prolegomena to formal axiology. But it contains suggestions that can be considered as profound intuitions of such axiology.

A pure axiology thus will not contain anything but $a$ priori statements of the formal determinations of that which in and by itself is evident as 'value,' without bothering whether this or that 'value' is willed; or what concretely is valuable; or in what inheres value; or how value is to be defined. In the same way pure logic does not contain anything but the formal determinations of what is evident as 'truth,' without bothering whether this 'truth' is recognized or known or not; or what materially is true; or in what inheres truth; or how it is to be defined. All self-evident propositions of formal $\operatorname{logic}(a=a$; when $a=a$ then a $\neq$ non- $a$, etc.) say nothing but constitutive matters of course. Thus any pure value proposition, as any intuitive axiom, must be self-evident. ${ }^{41}$

Not knowing the rules of formal axiology, but feeling his way toward them, Lessing, like Ortega y Gasset, believes that $a$ priori axiological rules are sui generis. The axiological investigations of value would therefore have to begin about as follows: supposing that there is the phenomenon value, what kind of relations can be stated with a priori validity in the same way as logical axioms (the laws of contradiction, of identity, and so forth.) can be stated for what we regard as true? $?^{42}$ Then Lessing presents the core questions of all axiology: 
But here appears immediately an obvious objection: are there special formal determinations for 'value in general'? Are they not maybe just modifications of those formal logical laws? Or rules valid for any kind of general manifolds? Is not 'value' carried by a value judgment just as truth is carried by a cognitive judgment? Are not then the formal determinations implied in the meaning of the objectively true and the objectively valuable both merely laws of correct judgment? ${ }^{43}$

Formal axiology answers this question in the affirmative: the formal rules of value are merely kinds of laws of correct judgment. They are modifications of ordinary logic. Formal axiology applies, precisely, the rules "valid for any kind of general manifold" to logical intensions, arriving thus at normative axiometric structures. Lessing, unfortunately, answers differently and takes a direction that does not permit his profound intuition of formal axiology to be developed. He believes that valuational thinking is so different from ordinary thinking that the same logic cannot be applied to it, that an entirely new logic has to be constructed, an axiologic totally sui generis. He does not see that every frame of reference must be logical and that the distinction between value logic and logic as such must be the same as that between mathematics and logic: it must be a species of logic. The only solution to Lessing's problem is to interpret value as a kind of logic, and to obtain a systematic framework by the axiomatic identification of value with an element of logic. An axiologic cannot be constructed without logic. The reason for Lessing's error is that he still thinks of value in terms too material, even though in a very slight manner, he commits the fallacy of method.

Pure axiology, he says, is as formal as formal logic or mathematics; and both these sciences must serve as models for the a priori laws of value. But, he maintains, a fundamental difference exists between axiological formality and logical or mathematical formality. "The formal statements about 'value' presuppose 'something' that has value in a totally different way from how the logical or the pure arithmetical laws presuppose that 'something' can be thought or counted." ${ }^{44}$ Here he commits the fallacy of method. He ought to have said that formal axiology presupposes other objects, that is, valueswhich are distinct from those that logic and arithmetic presuppose-propositions and acts of counting. Instead, he says that axiology presupposes its objects in an entirely different manner. He establishes thus a difference between the manner of presupposition rather than between the objects of the two kinds of science.

Lessing makes it clear that pure axiology ought to be completely independent of actual concrete values, that is, of its objects, and that "pure axiology is relatively, that is to say, with respect to any actual axiology, of a formal nature." ${ }^{\prime 45}$ If Lessing had seen that value could be defined by logic itself and the axiom of pure axiology be found by the identification of value with a con- 
stituent of logic, he would have seen that there is no difference between the formality of axiology and that of logic or arithmetic. Mathematics also arises by an axiomatic identification of something non-logical, namely numbers, with something non-logical, namely, classes. But this possibility never occurred to him, and he never established the exact analogy between the science of value and that of fact. The creative physicist, even though sometimes he invents his formal laws ad hoc, as for example Werner Heisenberg, finds in all such cases that what he invented either was an already developed field of arithmetic - in Heisenberg's case it was Cayley's matrices-or a new field of mathematics, like those opened up by Galileo or Newton.

Thus, even though Lessing polemicizes quite justifiably against Kant, in his own way he commits the same fallacy in believing that value is something so material that pure logic cannot explain it.

The axiological laws are actually specific laws toto genere different from logical laws. They are laws that concern the objective phenomenon of value (entirely independent from the actual being or not being of 'value'), laws which being so or being thus therefore cannot be explained exclusively as 'forms of judgment'!

Lessing had great difficulty conceiving that there ought to be laws that refer to the objective phenomenon of value and at the same time are independent from the reality of values. He does not see clearly the nature of axiological science-a science whose objects are "values" in the same way that the objects of natural science are "facts," and that natural science also is totally independent from, while at the same time applicable to, its objects, and that its judgments are both a priori and synthetic. Instead of basing his discussion on the notion of the Kantian synthetic a priori, Lessing bases it on the vague Kantian term "transcendental" with which he qualifies his axiology and which carries him down the road of no solution. It can lead to a "pure" and " $a$ priori" axiology in the sense of the Second Critique, but not to a formal axiology with systematic import in the sense of the metaphysic of the First Critique.

Thus, Lessing commits the same error as Kant. Although he sees clearly Kant's confusion of mixing axiological value with the will-the moral fallacy, he does not see the other confusion found in the ethics though not in the epistemology of Kant, that between pure formalism and ethical transcendentalism, the fallacy of method. Kant's "will" is transcendental; that is, it refers to, and determines, empirical acts of willing; but this determination is not $a$ priori in the sense of the First Critique, since the moral law itself lacks all the determination which the deductions give the categories. Lessing himself made this Bruch in the Kantian ethics clearer than anybody. ${ }^{47}$ Yet, although he rejects Kant's voluntarism, he accepts in his Wertaxiomatik Kant's diffuse transcendentalism, the undetermined reference to the empirical-a synthetic $a$ 
priori without a determined a priori, which is a reference without applicative force. See my discussion elsewhere of the distinction between reference and application. ${ }^{48}$ From this it follows that the basis of Lessing's "axiomatic" is analytic and not synthetic, that is, philosophical and not scientific. And hence follow his errors. "Formal laws," he says, "in the strict sense exist only in the pure theoretical sphere." ${ }^{49}$ Hence,

(1) the a priori laws of value cannot be formal in the same sense that pure math is, pure logic, pure syllogistic, pure number theory, and the pure theory of quantities and manifolds, etc., are. In the mathematical formula $a=a$ there is no material relation. It is schlechthin valid. But axiological laws are, so to speak, of a material kind, for 'value' is a predicate that needs a matter of which it is predicated. In logical laws of a purely formal kind such a relation is not inherent. There is no such reference. Therefore, value laws are relatively material laws which presuppose the more formal exactitude of logic. ${ }^{50}$

Here, again, is the fallacy of method. Lessing confuses 'value' and value. The subject of the purely formal proposition " $x$ is good" is a purely formal variable, just as is the predicate; but in the proposition "John is good" both subject and predicate are "material," for both are logical values of the variables (even though "good" looks the same in both cases). " $X$ is good" is an axiological proposition but a logical propositional function.

Lessing continues his analysis of axiology as a science sui generis distinct from logic:

(2) The logical laws are self-evident and analytic. We can express them exhaustively with algorithmic symbols, Euler diagrams, etc. Each of them is 'true.' They cannot collide as truths one with the other. In axiologic, on the other hand, there are no such self-evident truths. The reason is that there is no isolated value, as there is isolated evident truth. Rather, it is in the nature of value that each 'value' stands in a system of 'higher and lower'. Or, in other words: in every value there is the 'in comparison with.' There is no isolated value, no 'isol-value.' The axiological laws always refer to comparison or hierarchy. ${ }^{51}$

The answer to this argument of Lessing against the quasi-mathematical nature of value was given by Ortega y Gasset, who uses exactly the same argument for such nature. The comparison between values is precisely what makes possible, according to Ortega, a formal axiology, for it is similar to the comparison of inferior and superior in the hierarchy of numbers.

Actually, Lessing misunderstands the logical nature of the axiom: its creative power of a system isomorphic with reality. Hence, he cannot help but 
commit the fallacy of method again and again. His last argument for the difference between axiology and logic is (3) that valuative norms cannot be true because truths cannot have a hierarchy; one truth cannot be more true than another; but one value can be more valuable than another. He does not see that the value of a truth can be determined and defined by formal axiology, and that a truth can be worth more in one context than in another, for example in the subjective and the objective. Even in logic itself, truths can have different values, according to Lessing's own master, Edmund Husserl. ${ }^{52}$ (As explained in an earlier discussion, Daniel Christoff also bases his axiology on the value of logical judgments. $)^{53}$ Also, there is more truth in synthetic a priori than in synthetic judgments, more truth in a system as a whole than in a statement of the system, more truth in an axiom than in a category, and so on.

All statements within logical systems have the same truth. A truth is formally true in terms of the system of which it is part. Thus, the truth of the fact that $5>4$ is mathematical and derives its validity from its system. In the same way, the value $A>\mathrm{B}$ derives its truth from the axiological system that defines the greatness of value, as betterness, for example. One such truth is no more true than the other since consistent and logical systems have equal value, that is to say, the value of logical consistency. Hence, their truths also have equal value. Of course, truths cannot collide with truths; but neither can values with values. Truths can collide with falsities, and values with disvalues.

Lessing's argument against the identity of logic and axiology is therefore not valid either. He shows clearly his Kantian bias by telling us that even though axiology is not logic it is as a priori as logic, but the a priori of the practical or axiological region and that of the theoretical or logical region are different a prioris. That both are logics, but different ones, he does not see.

(4) Lessing's fourth argument is very ingenious. He concedes that the truth of axiology is as objective or absolute as that of mathematics or logic. "A truth is truth even though nobody understands it." The equations of mathematics and equivalencies in logic are true even though nobody understands them; and some equations of axiologic may be incomprehensible. ${ }^{54}$ Yet, there is a fundamental distinction between logic and axiology: logic itself can be axiologically analyzed. For this reason, he concludes, axiologic must not be reduced to logic. ${ }^{55}$ He thus shows that we must not commit the moral fallacy; we must not confuse value in general with a specific value. If logic can be a specific value, it cannot be value in general. ${ }^{56}$ This observation is profound and justified.

Formal axiology shows that there is an applied value logic; but this logic, as applied axiologic, is not the same as the logic of which axiology is itself the application. It is a new logic whose objects are not those of purely formal logic, but, for example, are such objects as the nature of the axiom and of the universal in general, valued logical objects. The universal, for example, is a concept intrinsically valued. While the concept is an object of logic, the 
universal is an object of logic as axiological science. The axiom is a similar object. It is the core of a field of phenomena intrinsically valued ${ }^{57}$ There are thus two logics, formal or systematic logic, and axiologically valued logic. The second is logic as applied axiology, and axiology itself is an application of the first. Valued logic is then an application of an application of formal logic.

It could also be said, and perhaps with more justification, that formal axiology is the overarching formal science since it contains formal logic as axiology of systemic value. ${ }^{58}$ This logic can, in turn, be valued, both extrinsically and intrinsically. The extrinsic valuation leads to pragmatic logics such as that of John Dewey, the intrinsic to organic logics like that of José Vasconcelos, phenomenologies such as Edmund Husserl's, vital logics like that of Ortega y Gasset, living logics as that of Carlos Vas Ferreira, the integral logic of Gabriel, and to metaphysical logics like those of Plato and Hegel. Mathematics, then, would be a species of systemic axiology. Thus the sciences, both natural and moral, would fit in the formal science of axiologic. Although Lessing does not have this grand vision for axiologic, he is clear not only about the possibility but the necessity of this new science. His errors are due to his lack of the axiological framework itself, whose forms he yet discerned with precision and whose future he foresaw.

It is up to us to bring about what he envisaged. 